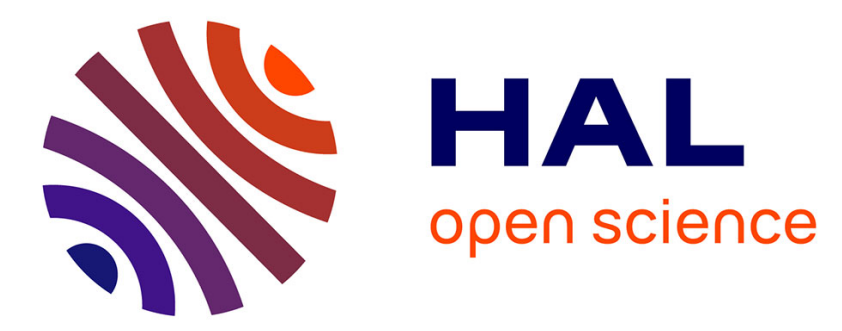

\title{
A Methodology and Tools for the Study of Composite Structures Under Impact Loading: Application to Long Fiber Laminated Structures
}

Francis Collombet, X. Lalbin, J.-L. Charles, G. Jeronimidis, J.-L. Lataillade

\section{- To cite this version:}

Francis Collombet, X. Lalbin, J.-L. Charles, G. Jeronimidis, J.-L. Lataillade. A Methodology and Tools for the Study of Composite Structures Under Impact Loading: Application to Long Fiber Laminated Structures. Journal de Physique IV Proceedings, 1997, 07 (C3), pp.C3-163-C3-168. 10.1051/jp4:1997330 . jpa-00255487

\section{HAL Id: jpa-00255487 https://hal.science/jpa-00255487}

Submitted on 1 Jan 1997

HAL is a multi-disciplinary open access archive for the deposit and dissemination of scientific research documents, whether they are published or not. The documents may come from teaching and research institutions in France or abroad, or from public or private research centers.
L'archive ouverte pluridisciplinaire HAL, est destinée au dépôt et à la diffusion de documents scientifiques de niveau recherche, publiés ou non, émanant des établissements d'enseignement et de recherche français ou étrangers, des laboratoires publics ou privés. 


\title{
A Methodology and Tools for the Study of Composite Structures Under Impact Loading: Application to Long Fiber Laminated Structures
}

\author{
F. Collombet, X. Lalbin, J.-L. Charles, G. Jeronimidis* and J.-L. Lataillade
}

\author{
LAMEF, École Nationale Supérieure d'Arts et Métiers, Esplanade des Arts et Métiers, \\ 33405 Talence cedex, France \\ * University of Reading, Department of Engineering, Whiteknights, P.O. Box 225, Reading RG6 2AY, \\ U.K.
}

\begin{abstract}
The aim of this paper is to present a method for taking into account, in numerical terms, the physics of damage events during impact of composite structures. The modeling of damage phenomena is based on the following choices : the use of an averaging model and a contact technique, and simple criteria to define the numerical conditions of initiation and extension of damage events. This approach is applied here to numerical modeling of the impact of ten plies symmetrical glass-epoxy 0/90 laminated plates where matrix cracking controls delamination and hence considered of primary importance.
\end{abstract}

\begin{abstract}
Résumé. Le but de cet article est de présenter une méthode pour rendre compte de la physique de l'endommagement sous impact de structures composites compte tenu des contraintes d'une modélisation éléments finis explicite 3D et du manque d'observations expérimentales au cours du temps. Les outils numérique pour la modélisation de l'endommagement sont présentés : homogénéisation, technique de contact et utilisation de critères pour définir les conditions numériques d'initiation et d'extension des événements endommageants. Cette méthode est appliquée à la simulation numérique de l'impact de plaques stratifiées dix plis verre époxyde $0 / 90$ où la fissuration de matrice pilotent le délaminage, ce qui souligne le nécessaire soin à apporter à sa modélisation.
\end{abstract}

\section{INTRODUCTION}

Impact on composite materials or systems is first of all a structural dynamics problem which leads to local damage phenomena. Many parameters are involved (the projectile mass, velocity, kinetic energy, the shape of the end of the impactor, the span of the target, boundary conditions) and this induces very different target responses depending on specific set of interactions [1]. Impact damage in composite structures has been studied extensively in recent years and a large number of papers, articles and reports on the subject are available in the literature [2]. But in the literature there exists no universal approach for the prediction or the representation of the behavior of composite structures under impact loading [2].

In the proposed approach, numerical calculations must be combined with experimental data to account for the three dimensional, multiscale and coupled characteristics of damage phenomena.

After a brief presentation of the theoretical and numerical backgrounds, a specific example is discussed, the impact of circular long fiber glass-epoxy $0 / 90$ symmetrical laminated plates, using a drop-weight set-up (an impactor with a hemispherical end, a mass of $2.3 \mathrm{~kg}$ and velocities less than $\left.6 \mathrm{~ms}^{-1}\right)$. In this case the only local damage events observed are transverse matrix cracking and delamination. With the help of a dynamic explicit finite element code, the experimental results lead to the numerical identification of local damage criteria which are conditions of initiation and propagation of local events. The coupling of impact experiments and dynamic explicit calculations permits to implicitly take into account the influence of dynamic effects on damage evolution through the identification of the values of the parameters of the damage criteria

\section{THEORETICAL AND NUMERICAL BACKGROUNDS}

The response of composite plates under low velocity impact loading is modeled with the dynamic explicit finite element code PLEXUS. The numerical time integration scheme of Newmark used in its explicit formulation results in a condition of stability which links the time step $\Delta t$ with the smallest dimension of the mesh $L_{\text {nino }}$. 
Matrix cracking is modeled by means of an averaging technique developed on the scale of a finite element [3]. It accounts for the average effects of cracks in the finite element, by calculating elastic characteristics of a homogenized undamaged material equivalent to the initial material containing cracks. This choice leads to a numerical effect of cracks which depends on the meshing, but it is balanced, in relation to the size of the element, by the introduction of a dilution parameter linked to the number of cracks in the element, and the size of the element.

Maximum stress criteria are used to start off numerical cracking and its effects. Since the effect of the stress concentration at the tip of the cracks is not evaluated in the finite element analysis, an extension criterion is added.

Delamination is treated by means of a contact technique based on Lagrange multipliers [4]. The assembly of the different layers of the structure is obtained via nodal link forces (double nodes of the mesh). The delamination is represented by an effective local separation between the different layers (i.e. loss of contact) which differs from a classical Fracture Mechanics energy-based approach. In the same way the contact technique is used for the determination of the impact force applied by the impactor to the target. The necessary condition for delamination to occur is a critical value of the link force in the direction $\alpha$ of propagation of delamination : $F_{\alpha}>F^{\text {critical }}$. This is not the only condition for delamination ; physical considerations based on experimental observations specific to the material and structure problem treated need also to be integrated with the numerical condition.

These tools, finite element code, cracking and delamination models, and contact-impact technique can be used for the representation of different problems of composite structures under impact loading. Each particular problem requires a specific experimental study in order to postulate the form of the numerical criteria which will start off damage events : conditions of initiation and evolution. First the mechanisms of degradation of the composite structures have to be identified relatively to the scale of the calculations. The experimental data obtained have then to be translated in numerical conditions for the finite element analysis. The methodology is here applied to the case of the impact of circular long fiber glass-epoxy $0 / 90$ plates of $200 \mathrm{~mm}$ diameter.

\section{EXPERIMENTAL STUDY : IMPACT OF GLASS/EPOXY LAMINATES}

The plates are circular $(\varnothing 200 \mathrm{~mm})$ with a thickness of $1.8 \mathrm{~mm}$, and are made by stacking of ten unidirectional plies with different orientations which are noted $\left[0_{\mathrm{n}} / 90_{\mathrm{m}} / 0_{\mathrm{n}}\right]$, where $\mathrm{n}+\mathrm{m}=10$, with $\mathrm{n}=2,3$ and 4 .

The elastic properties of a glass/epoxy unidirectionnal laminate ( 1 for fiber direction, 2 and 3 for transverse directions) are: $\mathrm{E}_{1}=30.5 \mathrm{GPa}, \quad \mathrm{E}_{2}=6.9 \mathrm{GPa}, \quad v_{12}=0.344$, $v_{21}=0.078, \quad v_{23}=0.46, \quad \mathrm{G}_{12}=4.65 \mathrm{GPa}$, $\mathrm{G}_{23}=1.6 \mathrm{GPa}$. The plates are impacted in their center by a cylindrical steel projectile of $2.3 \mathrm{~kg}$ mass with a hemispherical end (Figure 1). They are clamped on their periphery over a $20 \mathrm{~mm}$ wide ring. The output signals are the applied normal force $F(t)$ and the displacement $d(t)$ of the extremity of the projectile as a function of time.

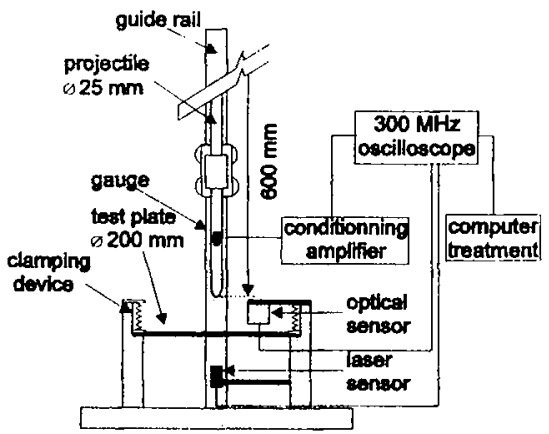

Figure 1 : Drop weight set-up. 
The typical damage events of the $\left[0_{\mathrm{n}} / 90_{\mathrm{m}} / 0_{\mathrm{n}}\right]$ plates under this impact type are illustrated in Figure 2 for the case of a $27 \mathrm{~J}$ impact (mass $2.3 \mathrm{~kg}$, velocity $4.85 \mathrm{~ms}^{-1}$ ) on a $\left[0_{3} / 90_{4} / 0_{3}\right]$ plate. No fiber rupture is observed, unlike what has been observed in static indentation tests for the same boundary and contact conditions [5]. The transparency of the layers made of epoxy matrix and glass fibers allows a visual inspection. In accordance with earlier reported studies [6], two different kinds of damage are observed :

-two butterfly wing-shaped delamination areas at $0 / 90$ interfaces propagating in the fiber direction of the adjacent layer (i.e. group of plies of same orientation) farthest from the impact point

-longitudinal matrix cracks (parallel to the fibers of a layer), going all through the thickness of a layer.

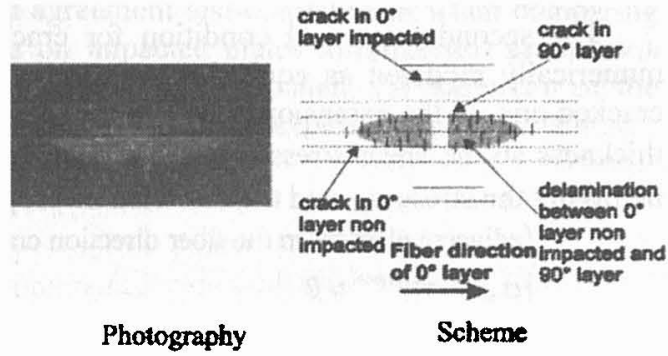

Figure 2 : Damage observations in the plane of the plate of a $\left[0_{4} / 90_{2} / 0_{4}\right]$ plate impacted at $27 \mathrm{~J}$ (scale 0.4 ).

Visual inspection shows two types of matrix cracks networks depending on the layer position within the plate thickness. As regards the average length of cracks, the number of cracks in each layer and the two different types of propagation of cracks in the thickness of a layer, we propose to distinguish, in the numerical modeling, cracking phenomena linked to two different kinds of layer :

- layer with at least one face free of overall constraints (i.e. $0^{\circ}$ layer)

- layer with both faces constrained (i.e. $90^{\circ}$ layer).

The delamination propagation mode seems mainly a mode-II rupture considering the matrix rupture combined to "fibers of lower layer"-"matrix of upper layer" unsticking [5]. Moreover delamination occurs when the layers on each side of the interface are locally cracked. In consequence, the quality of the numerical treatment of delamination is very dependent on the numerically modeled cracking. The importance of a precise numerical representation of matrix cracking cannot be underestimated.

\subsection{Damage chronology and numerical conditions}

In order to perform numerical calculations we have to postulate a damage chronology which will necessarily be an interpretation of the evolution of physical events. As many authors have indicated it, the values of the contact force are important parameters in considering impact damage resistance [7]. We associate the thresholds of energy for the appearance (to the naked eye) of first damages after impact with the corresponding force level. For a $1 \mathrm{~J}$ impact, first cracking in $0^{\circ}$ layer and the maximum value $F_{\max 1}$ of the resultant force applied by the projectile versus time $F(t)$ is noted. In the same way we check $F_{\max 2}$ for a $3 \mathrm{~J}$ impact together with first cracking in $90^{\circ}$ layer and first delamination.

On the basis of these experimental observations we propose the following chronology for the numerical appearance of damages versus time, whatever the stacking sequence $\left[0_{n} / 90_{m} / 0_{n}\right](n=2,3$ and $4, n+m=10)$. At $F(t)$ equal to $F_{\max 1}$ first cracks are initiated in the $0^{\circ}$ layer farthest away from the impact location. When $F(t)$ reaches $F_{\max 2}$ the $90^{\circ}$ layer starts cracking. At $F(t)$ equal to $F_{\max 2}$ after the $90^{\circ}$ layer has begun cracking, delamination appears.

The first numerical condition for cracking is an initiation criterion involving transverse bending stress $\sigma_{22}$ and shear stress $\sigma_{23}$, similarly to that found in the literature [8]. The stress $\sigma_{22}$ represents 
the opening of the crack due to traction [9] and the stress $\sigma_{23}$ is related to the immediate propagation of the crack in the thickness due to shearing. With the stresses expressed in the local system of coordinates of each finite element the initiation criterion is expressed as follows :

$$
\left\{\begin{array}{l}
\sigma_{22}>\sigma_{22}^{\text {initation }}>0 \\
\left|\sigma_{23}\right|>\sigma_{23}^{\text {initiation }}
\end{array}\right.
$$

The second numerical condition for cracking is an extension criterion. Crack extension is numerically modeled as equivalent to the creation of a new crack in an element adjacent to a cracked one. In the extension phase, in the plane of the layer, the crack already extends through the thickness so the shear stress $\sigma_{23}$ is not considered. This leads to a form of the extension criterion involving the stress $\sigma_{22}$ and the direction of propagation of the cracks (fiber direction) :

$$
\left\{\begin{array}{l}
\text { adjacent element in the fiber direction cracked and } \\
\sigma_{22}>\sigma_{22}^{\text {extension }}>0
\end{array}\right.
$$

Eq. 2

This criterion is applied only in the elements adjacent to a cracked one in the fiber direction. Because it is physically " easier » (due to stress concentration at the tip of cracks) for a crack to be extended than to be created, the numerical value will be different from the initiation criterion values.

In the analytic form of the initiation criterion no distinction is made between cracking in the layers with one face constrained (i.e. $0^{\circ}$ layers) and the layer with two faces constrained (i.e. $90^{\circ}$ layer). But the stress values will be different according to the fact that matrix cracking does not involve the same growth phenomenon in the thickness of the different layers. In the same way we can use the extension criterion for the $90^{\circ}$ layer but with the threshold value of the criterion different from the one of the $0^{\circ}$ layers.

In our study, the length in the fiber direction of the cracks in the $90^{\circ}$ layer is smaller than the size of the chosen finite elements, and it is therefor unnecessary to apply the extension criterion in the specific numerical study presented here.

Moreover, according to experimental observations, we link the values of the criteria applicable to a type of layer to its thickness by the following relations :

$$
\begin{array}{ll}
\sigma_{23}{ }^{\text {initation }} / \mathrm{e}=\mathrm{c}_{\alpha}{ }^{\text {initiation }} & : \text { the thinner the layer, the easier the cracking } \\
\sigma_{22}{ }^{\text {extension }} . \mathrm{e}=\mathrm{c}^{\text {extension }} & : \text { the thicker the layer, the longer the cracks }
\end{array}
$$

where $\sigma_{23}{ }^{\text {initiation }}$ and $\sigma_{22}{ }^{\text {extension }}$ are critical values for a given thickness e of the layer, and $c_{\alpha}{ }^{\text {initiation }}$ and $c^{\text {extension }}$ are constants independent of the thickness, but $c_{\alpha}{ }^{\text {initiation }}$ is a function of the parameter $\alpha$ which is the number of constrained faces : $\alpha=1\left(0^{\circ}\right)$ or $2\left(90^{\circ}\right)$.

Note that the condition for the numerical delamination has to take into account experimental observations. The following conditions must be verified at the relevant location : at a given interface a double node is numerically authorized to separate if, for the lower layer all adjacent finite elements are cracked and, for the upper layer one adjacent finite element is cracked or one adjacent double node is already separated. These conditions take into consideration respectively the precursor effect of the cracking on the delamination and the observation that delaminated surface can exist without cracking in the upper layer.

\section{EXPERIMENTAL AND NUMERICAL RESULTS : COMPARISON}

Each layer of the plate is modeled by one element in the thickness and 308 hexahedral linear $C^{n}$ elements (brick element with eight nodes, three degrees of freedom per node and 1 and 8 integration points) in the plane of the plate. Because of the $0 / 90$ lay-up, the finite elements directions at the 
center of the plate can correspond with the principal orientations of the laminate as requested by the crack extension criterion. The contact projectile/target is very simplified as a node and the projectile is represented as a weighted point with initial velocity [3].

Calculations for $27 \mathrm{~J}$ impact energy on three plates of different stacking sequence integrated with complete damage modeling, validates the criteria values (Table I) identified by our method. Accordingly the final state of damage shows a good agreement test-computation when comparing the interpretation of visual observations of damages on impacted plates to numerical predictions (Figure 3). Although the cracking in $90^{\circ}$ layer is somehow approximated, the hierarchy of the delamination area for the different staking is conserved with respects to experimental observations.
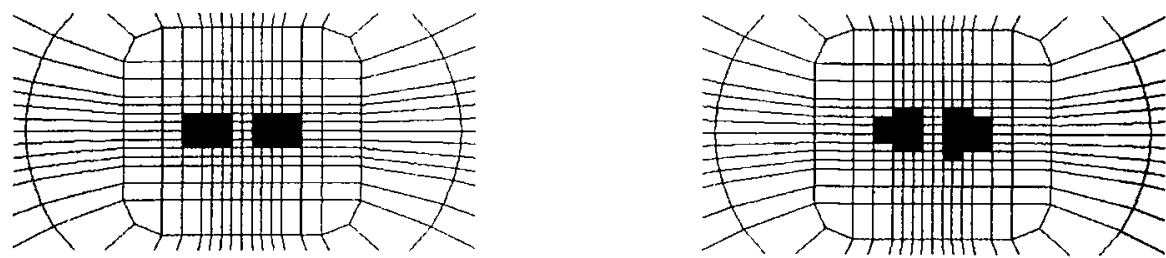

Delamination between the $90^{\circ}$ layer and the non impacted $0^{\circ}$ layer for $\left[0_{2} / 90_{6} / 0_{2}\right]$ plate
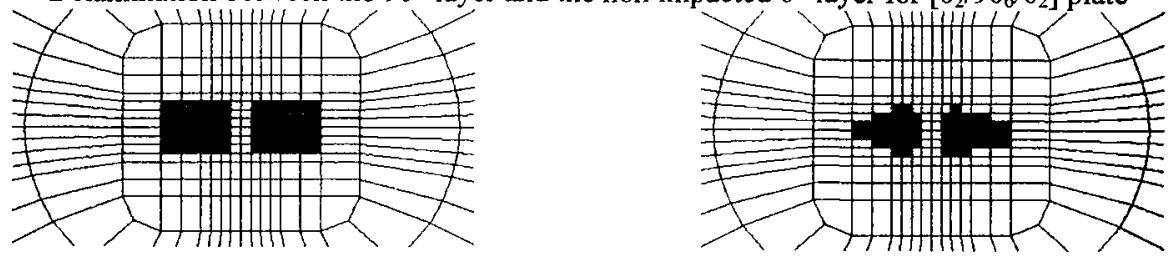

Delamination between the $90^{\circ}$ layer and the non impacted $0^{\circ}$ layer for $\left[0_{3} / 90_{4} / 0_{3}\right]$ plate
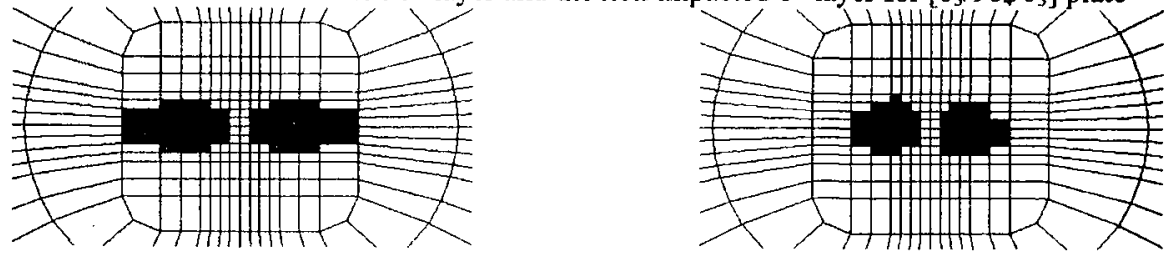

Delamination between the $90^{\circ}$ layer and the non impacted $0^{\circ}$ layer for $\left[0_{4} / 90_{2} / 0_{4}\right]$ plate

Gray scale of delamination: 1 to 3 delaminated nodes, $\mathbf{a}$ delaminated nodes

Figure 3 : Comparison between numerical delamination (left, scale 0.6) and experimental delamination (right, scale 0.6) for $27 \mathrm{~J}$ impacts $(\mathrm{m}=2,3 \mathrm{~kg}, \mathrm{v}=5 \mathrm{~m} / \mathrm{s})$ on three glass-epoxy $\left[0_{n} / 90_{\mathrm{m}} / 0_{\mathrm{n}}\right]$ laminates, $\mathrm{n}+\mathrm{m}=10, \mathrm{n}=2,3$ and 4. Partial view of the central part of the plates.

Table I : Values of the damage criteria for the three different stacking

\begin{tabular}{|c|c|c|c|c|c|c|}
\hline $\begin{array}{c}\text { Critical } \\
\text { values of }\end{array}$ & $\begin{array}{c}\sigma_{22}{ }^{\text {initiation }} \\
0^{\circ} \mathrm{ply}\end{array}$ & $\begin{array}{c}\sigma_{23}{ }^{\text {initiation }} \\
0^{\circ} \mathrm{ply}\end{array}$ & $\begin{array}{c}\sigma_{22}{ }^{\text {exterision }} \\
0^{\circ} \text { ply }\end{array}$ & $\begin{array}{c}\sigma_{22}{ }^{\text {initiation }} \\
90^{\circ} \text { ply }\end{array}$ & $\begin{array}{l}\sigma_{23}{ }^{\text {initiation }} \\
90^{\circ} \text { ply }\end{array}$ & $\begin{array}{c}\text { delamination } \\
F^{\text {critical }}\end{array}$ \\
\hline$\left[0_{2} / 90_{6} / 0_{2}\right]$ & $85 \mathrm{MPa}$ & $12 \mathrm{MPa}$ & $57 \mathrm{MPa}$ & $26 \mathrm{MPa}$ & $21 \mathrm{MPa}$ & $200 \mathrm{~N}$ \\
\hline$\left[0_{3} / 90_{4} / 0_{3}\right]$ & $85 \mathrm{MPa}$ & $18 \mathrm{MPa}$ & $38 \mathrm{MPa}$ & $26 \mathrm{MPa}$ & $15 \mathrm{MPa}$ & $200 \mathrm{~N}$ \\
\hline$\left[0 / 90_{2} / 0_{4}\right]$ & $85 \mathrm{MPa}$ & $23 \mathrm{MPa}$ & $27 \mathrm{MPa}$ & $26 \mathrm{MPa}$ & $8 \mathrm{MPa}$ & $200 \mathrm{~N}$ \\
\hline
\end{tabular}




\section{CONCLUSION}

The scientific strategy which has been developed is based on three main lines of approach, experimental, numerical and theoretical, with various interconnections between them. Using tools based on an explicit Finite Elements dynamic code, this method provides the means to analyze the experimental conditions and to model the events which cannot be detected experimentally in real time. The theoretical aspects are underpinned by the development of tools specifically designed to describe the behavior of composite materials, globally or locally heterogeneous. In addition, contact problem techniques are exploited in a context of dynamic behavior : for the numerical representation of the impact loading and for the behavior of interfaces (debonding).

The applicability of the method can be improved in different ways. First the sensitivity of the method to the mesh has to be evaluated. In the same way the modeling of the entire impactor leading to a contact surface has to be considered. For a given mesh a parametric study of the influence of the thresholds identified for the cracking criteria on the final results has to be carried out. This methodology can be extended to other composite systems and multi-material assemblies, but requires the development of experimental tools and procedures associated to the structures studied and the damage events occurring.

\section{REFERENCES}

[1] : Pécault S., 1996, "Impact tolerance of sandwich structures and scale effects", Ph. D. thesis (in french), Ecole Nationale Supérieure d'Arts et Métiers CER Bordeaux, n96/37.

[2] : Abrate S., 1994, "Impact on laminated composites : Recent advances", Appl. Mech. Rev., Vol. 47 , issue $\mathrm{n}^{\circ} 11$, pp. 517-544.

[3] : Collombet F., Bonini J., Lataillade J.L., 1996a, "A three-dimensional modeling of low velocity impact damage in composite laminates", in Int. J. for Numerical Methods in Engineering, Vol. 39. issue $\mathrm{n}^{\circ} 9$, pp. 1491-1516.

[4] : Collombet F., Lalbin X., Bonini J., Lataillade J.L., 1996b, "Contact impact techniques for the study of impacted laminated structures", accepted for publication in a Special Issue of Mathematical and Computer Modeling.

[5] : Collombet F., Bonini J., Auzanneau T., Lataillade J.L., 1995a, "Analyse comparée de la réponse de plaques stratifiées composites au poinçonnement statique et à l'impact basse vitesse", Mécanique Industrielle et Matériaux, $\mathrm{Vol} 48$, issue $\mathrm{n}^{\circ} 2$, June, pp. 96-98.

[6] : Sierakowski R.L., Malvern L.E. and Ross C.A., 1976, "Dynamic failure modes in impacted composite plates", in Failure modes in composite III, TT Chia (ed.), AIME, New-York, pp. 73-88.

[7] : Lagace P.A. and Wolf E., 1993, "Impact damage resistance of several laminated systems", 34th AIAA Struct, Struct. Dynamics and Material Conference, La Jolla CA, Pt 4, pp. 1863-1872.

[8] : Choi H.Y. and Chang F.K., 1992, "A model for predicting damage in graphite/epoxy laminated composites resulting from low-velocity point impact", in Journal of Composite Materials, Vol. 26, issue $\mathrm{n}^{\circ} 14$, pp. $2134-2169$.

[9] : Degrieck J., 1990, "Analyse van impact op een vezelversterkte kunststof" (Analysis of impact on fiber reinforced plastic), Ph.D. thesis (in dutch), University of Ghent, Belgium. 